\title{
Application of the Critical Heat Flux Look-Up Table to Large Diameter Tubes
}

\author{
M. El Nakla, ${ }^{1}$ M. Habib, ${ }^{1}$ W. Ahmed, ${ }^{1}$ A. Al-Sarkhi, ${ }^{1}$ R. Ben Mansour, ${ }^{1}$ and M. Y. Al-Awwad ${ }^{2}$ \\ ${ }^{1}$ Mechanical Engineering Department, King Fahd University of Petroleum and Minerals, Dhahran 31261, Saudi Arabia \\ ${ }^{2}$ Consulting Services Department, Saudi Aramco Oil Company, Dhahran 31261, Saudi Arabia \\ Correspondence should be addressed to M. El Nakla; elnakla@kfupm.edu.sa
}

Received 13 August 2013; Accepted 10 September 2013

Academic Editor: Atef Mohany

Copyright (C) 2013 M. El Nakla et al. This is an open access article distributed under the Creative Commons Attribution License, which permits unrestricted use, distribution, and reproduction in any medium, provided the original work is properly cited.

\begin{abstract}
The critical heat flux look-up table was applied to a large diameter tube, namely $67 \mathrm{~mm}$ inside diameter tube, to predict the occurrence of the phenomenon for both vertical and horizontal uniformly heated tubes. Water was considered as coolant. For the vertical tube, a diameter correction factor was directly applied to the 1995 critical heat flux look-up table. To predict the occurrence of critical heat flux in horizontal tube, an extra correction factor to account for flow stratification was applied. Both derived tables were used to predict the effect of high heat flux and tube blockage on critical heat flux occurrence in boiler tubes. Moreover, the horizontal tube look-up table was used to predict the safety limits of the operation of boiler for $50 \%$ allowable heat flux.
\end{abstract}

\section{Introduction}

Critical heat flux (CHF) is a phenomenon corresponding to the point where a continuous liquid contact cannot be maintained at the heated surface. Strictly speaking, this particular term refers to the heat flux corresponding to the occurrence of the phenomenon. Other terms often used are burnout, dryout, boiling crisis, and departure from nucleate boiling (DNB).

CHF results in sudden drop in heat transfer rate between the heated surface and the coolant. Beyond CHF, a small increase in heat flux leads to large increase in surface temperature for a heat-flux-controlled surface (e.g., electric heaters), and a small increase in surface temperature leads to decrease in heat flux for a temperature-controlled surface (e.g., steam condensers). This could lead to overheating damaging of the surface, corrosion in the CHF region, and reduction in the operating efficiency.

Various prediction methods for $\mathrm{CHF}$ have been proposed during the past 60 years. The earliest prediction methods were primarily empirical $[1,2]$. These crude empirical correlations lacked any physical basis and had a limited range of application. Subsequently, a large number of phenomenological equations or physical models for CHF were developed; many of these models were subsequently used in the safety analysis of nuclear reactors, boilers, and steam generators. Physical models, however, depend on the mechanisms controlling the $\mathrm{CHF}$, which are flow-regime dependent. Flow regimes change significantly during a typical transient, and this necessitates the use of a combination of different models, equations, or correlations for CHF in safety analysis codes. Since most empirical CHF correlations and models have a limited range of application, the need for a more generalized technique is obvious. Hence, look-up tables (LUTs) for predicting CHF were subsequently derived. As a basis of the generalized technique, the common local-conditions hypothesis was used; that is, it was assumed that the CHF for a water-cooled tube with a fixed tube diameter is a unique function of local pressure $(P)$, mass flux $(G)$, and thermodynamic quality $(x)$.

The CHF-LUT is basically a normalized water CHF data bank for vertical tubes with $8 \mathrm{~mm}$ in tube diameter. Compared to other available prediction methods, the LUT approach has the following advantages: (i) greater accuracy, (ii) wider range of application, (iii) correct asymptotic trend, (iv) requires less computing time, and (v) can be updated if additional data become available. The greatest potential for the CHF-LUT approach is its application in predicting the consequences of pipe breakage in reactors and boilers. 
The following sections describe the background, the derivation, and the application of the CHF-LUT to predict $\mathrm{CHF}$ occurrence in vertical and horizontal large-diameter tubes. The CHF-LUTs specifically for $67 \mathrm{~mm}$ diameter tubes were generated in this work covering wide range of flow conditions of pressure, mass flux, and thermodynamic quality.

\section{Predicting CHF in Vertical Tube}

2.1. Analysis. Groeneveld et al. [3] combined the CHF data of both Atomic Energy of Canada Limited and the Institute of Physics and Power Engineering in the Russian Republic (a total of over 30000 points) and updated the look-up table for tubes. The new table (1995 CHF-LUT) provides a better prediction accuracy (root-mean-squared error of $7.82 \%$ for dryout power prediction against 25,630 CHF experimental data points from 49 different experiments) than other lookup tables and correlations over the complete range of flow conditions. In addition, Groeneveld et al. [3] employed a multidimension smoothing procedure of Huang and Cheng [4], which has eliminated several irregularities in the parametric trends.

The 1995 tube CHF-LUT as well as the earlier versions of the LUT have been assessed extensively. The most recent assessment was made by Baek et al. [5] using their database. Their assessment confirms the error statistics reported by Groeneveld et al. [3] and the improved prediction capability compared with previous versions of the table. Earlier assessments by Smith [6] and the developers of the RELAP code indicated the suitability of the table look-up approach and resulted in its use in system codes such as CATHARE [7], THERMOHYDRAULIK [8], and RELAP [9]. Considering all of these reasons, the $1995 \mathrm{CHF}-\mathrm{LUT}$ was selected as the base of the current analysis for predicting CHF in vertical tubes.

The 1995 CHF-LUT was built for water upward flow in $8 \mathrm{~mm}$ diameter vertical tube. To use the table for other tube diameters, Groeneveld et al. [3] derived a diameter correction factor $\left(K_{\text {dia }}\right)$ such that for $0.002 \mathrm{~m} \leq D_{\text {hy }} \leq 0.025 \mathrm{~m}$,

$$
K_{\text {dia }}=\left(\frac{0.008}{D_{\text {hy }}}\right)^{0.5} \text {, }
$$

and for $D_{\text {hy }}>0.025 \mathrm{~m}$,

$$
K_{\text {dia }}=0.57 \text {. }
$$

This correction factor can be multiplied by the CHF values of 1995 CHF-LUT to get the corresponding CHF for non- $8 \mathrm{~mm}$ diameter tube as follows:

$$
\mathrm{CHF}_{\mathrm{ver}}=K_{\mathrm{dia}} \cdot \mathrm{CHF}_{\mathrm{ver}, 8 \mathrm{~mm}} \text {. }
$$

2.2. Discussion. The 1995 CHF-LUT along with (2) (for $D_{\text {hy }}=$ $0.067 \mathrm{~m}$ ) were used to derive a modified LUT suitable for the current application. Table 1 shows the derived LUT using (3) and the 1995 CHF-LUT. This table has flow-condition limits other than the original table to suit the current application. The ranges of flow parameters are limited to pressures of 100$7000 \mathrm{kPa}$, mass fluxes of $100-2000 \mathrm{~kg} \cdot \mathrm{m}^{-2} \cdot \mathrm{s}^{-1}$, and qualities of $-0.15-0.8$.
Figure 1 shows pressure effect on the predicted CHF value at low, low-to-moderate and moderate, mass fluxes. At low mass flux (Figure 1(a)), there is no apparent effect of pressure on CHF. At low-to-moderate and moderate mass fluxes (Figures 1(b) and 1(c)), however, evident pressure effect was observed. For the low-to-moderate quality region $(<\sim 0.35)$, which is the region of interest, CHF increases with decreasing pressure. This is similar to what is reported in the literature (e.g., [10]).

The effect of mass flux on CHF is shown in Figure 2. Similar to pressure effect, $\mathrm{CHF}$ increases with increasing mass flux then starts decreasing. The decrease in this region in $\mathrm{CHF}$ is due to the vapor generation rate and the interaction between vapor and liquid at the interface (see also [10]).

As an example of the application of the LUT approach on predicting the safe operation of boilers, consider the results shown in Table 2. For the base case, which represents the normal operating conditions of an actual boiler, $\mathrm{CHF}$ is unlikely to occur because it is 32 times higher than the operating heat flux. When the operating heat flux is increased by four times, the exit quality increased which results in reduction in $\mathrm{CHF}$ value. Even with that increase in operating heat flux, the CHF value is still much higher (6 times) than the operating heat flux. The final case is with $90 \%$ blockage of the tube which will result in reduction in mass flux and increase in quality. Table 2 shows that even with this amount of blockage it is still unlikely for CHF to occur.

\section{Predicting CHF in Horizontal Tube}

3.1. General Considerations. CHF prediction for a horizontal flow differs from that of vertical flow. For horizontal flow, flow stratification effect appears as a result of gravitational forces. For instance, in annular flow regime of vertical upward flow, the liquid film is said to be uniformly distributed (has the same thickness) on the tube wall. In the same flow regime of horizontal flow, the liquid film has greater flow thickness at the bottom of the tube while it is thinner on the upper part (Figure 3). This will dramatically decrease the heat flux value at which $\mathrm{CHF}$ occurs specially at low mass fluxes and large tube diameters $\left(G<2000 \mathrm{~kg} \cdot \mathrm{m}^{-2} \cdot \mathrm{s}^{-1}, D_{\text {hy }}>25 \mathrm{~mm}\right)$ [3]. At high mass fluxes and smaller tube diameters, $\mathrm{CHF}$ is predicted for horizontal tubes in the same manner as in vertical tubes.

To improve the value of CHF for horizontal flow, Collier and Thome [10] suggested the use of flow enhancers such as twisted tape tube inserts and replacing the tubes by microfinned tubes (see Figure 4). For twisted tapes, heat transfer augmentation ratios are typically in the range from 1.2 to 1.5 while the two-phase pressure drop ratios are often as high as 2.0 because the tape divides the flow area into two smaller areas with smaller hydraulic diameters. By using the microfinned tube, heat transfer enhancements can be as high as three to four times for horizontal flow with low mass fluxes. Two-phase pressure drop ratios range from 1.0 at low mass fluxes up to a maximum of 1.5 at high mass fluxes. 
TABLE 1: CHF-LUT for vertical up-flow in $67 \mathrm{~mm}$ diameter tube.

\begin{tabular}{|c|c|c|c|c|c|c|c|c|c|c|c|c|c|c|c|}
\hline \multirow{3}{*}{$P(\mathrm{kPa})$} & \multirow{3}{*}{$G\left(\mathrm{~kg} \cdot \mathrm{m}^{-2} \cdot \mathrm{s}^{-1}\right)$} & \multicolumn{14}{|c|}{ Quality, $x(-)$} \\
\hline & & -0.15 & -0.10 & -0.05 & 0.00 & 0.05 & 0.10 & 0.15 & 0.20 & 0.30 & 0.40 & 0.50 & 0.60 & 0.70 & 0.80 \\
\hline & & \multicolumn{14}{|c|}{ Critical heat flux, CHF $\left(\mathrm{kW} \cdot \mathrm{m}^{-2}\right)$} \\
\hline 100 & 100 & 2967 & 2351 & 1677 & 1110 & 661 & 648 & 640 & 631 & 618 & 610 & 591 & 548 & 426 & 314 \\
\hline 100 & 500 & 2999 & 2454 & 2148 & 1826 & 1163 & 1076 & 1073 & 1069 & 983 & 921 & 834 & 677 & 429 & 318 \\
\hline 100 & 1000 & 3071 & 2637 & 2354 & 2010 & 1441 & 1303 & 1300 & 1260 & 1156 & 943 & 930 & 817 & 485 & 244 \\
\hline 100 & 1500 & 3096 & 2698 & 2403 & 2055 & 1512 & 1383 & 1371 & 1306 & 1188 & 1058 & 1058 & 910 & 478 & 198 \\
\hline 100 & 2000 & 3097 & 2701 & 2404 & 2061 & 1535 & 1418 & 1394 & 1330 & 1171 & 1093 & 1035 & 836 & 384 & 104 \\
\hline 1000 & 100 & 3240 & 3010 & 2765 & 2433 & 1930 & 1595 & 1511 & 1443 & 1306 & 1163 & 971 & 748 & 736 & 713 \\
\hline 1000 & 500 & 4176 & 4091 & 4053 & 4017 & 3886 & 3289 & 2904 & 2656 & 2198 & 1302 & 946 & 590 & 470 & 437 \\
\hline 1000 & 1000 & 4178 & 4099 & 4061 & 4003 & 3822 & 3246 & 2874 & 2641 & 1860 & 1160 & 864 & 546 & 337 & 258 \\
\hline 1000 & 1500 & 4189 & 4121 & 4077 & 3997 & 3764 & 3153 & 2844 & 2521 & 1845 & 887 & 530 & 363 & 234 & 211 \\
\hline 1000 & 2000 & 4232 & 4150 & 4099 & 3997 & 3649 & 2962 & 2690 & 2510 & 1792 & 783 & 406 & 308 & 196 & 78 \\
\hline 2000 & 100 & 3301 & 3132 & 2944 & 2658 & 2140 & 1796 & 1703 & 1629 & 1487 & 1330 & 1160 & 998 & 920 & 809 \\
\hline 2000 & 500 & 4241 & 4195 & 4200 & 4181 & 4079 & 3640 & 3276 & 2941 & 2469 & 1618 & 1420 & 1077 & 760 & 595 \\
\hline 2000 & 1000 & 4243 & 4201 & 4173 & 4142 & 4032 & 3574 & 3206 & 2922 & 2127 & 1457 & 1178 & 822 & 523 & 365 \\
\hline 2000 & 1500 & 4254 & 4215 & 4168 & 4118 & 3948 & 3475 & 3126 & 2698 & 2003 & 1211 & 758 & 489 & 296 & 248 \\
\hline 2000 & 2000 & 4293 & 4232 & 4174 & 4078 & 3740 & 3198 & 2860 & 2540 & 1889 & 1041 & 548 & 327 & 204 & 133 \\
\hline 3000 & 100 & 3361 & 3254 & 3123 & 2882 & 2349 & 1996 & 1896 & 1816 & 1668 & 1496 & 1349 & 1249 & 1104 & 905 \\
\hline 3000 & 500 & 4306 & 4298 & 4347 & 4344 & 4273 & 3990 & 3648 & 3226 & 2740 & 1933 & 1895 & 1565 & 1049 & 752 \\
\hline 3000 & 1000 & 4309 & 4302 & 4285 & 4282 & 4243 & 3902 & 3539 & 3203 & 2394 & 1755 & 1492 & 1097 & 708 & 473 \\
\hline 3000 & 1500 & 4319 & 4309 & 4258 & 4239 & 4133 & 3797 & 3409 & 2875 & 2161 & 1534 & 985 & 616 & 357 & 284 \\
\hline 3000 & 2000 & 4355 & 4313 & 4248 & 4160 & 3832 & 3435 & 3030 & 2569 & 1986 & 1299 & 690 & 347 & 213 & 188 \\
\hline 4000 & 100 & 3315 & 3215 & 3097 & 2885 & 2362 & 2027 & 1933 & 1853 & 1706 & 1547 & 1380 & 1280 & 1164 & 953 \\
\hline 4000 & 500 & 4114 & 4093 & 4115 & 4093 & 3959 & 3629 & 3333 & 3089 & 2678 & 2100 & 1946 & 1649 & 1226 & 880 \\
\hline 4000 & 1000 & 4134 & 4097 & 4064 & 4021 & 3862 & 3565 & 3277 & 3014 & 2384 & 1860 & 1626 & 1137 & 762 & 531 \\
\hline 4000 & 1500 & 4162 & 4109 & 4041 & 3955 & 3713 & 3414 & 3101 & 2728 & 2113 & 1617 & 1101 & 648 & 439 & 398 \\
\hline 4000 & 2000 & 4212 & 4136 & 4003 & 3821 & 3416 & 3079 & 2770 & 2420 & 1907 & 1378 & 725 & 364 & 292 & 279 \\
\hline 5000 & 100 & 3268 & 3177 & 3071 & 2887 & 2374 & 2057 & 1971 & 1890 & 1745 & 1598 & 1411 & 1311 & 1224 & 1001 \\
\hline 5000 & 500 & 3923 & 3887 & 3883 & 3841 & 3645 & 3268 & 3019 & 2951 & 2615 & 2266 & 1997 & 1733 & 1402 & 1008 \\
\hline 5000 & 1000 & 3958 & 3893 & 3844 & 3759 & 3481 & 3227 & 3015 & 2825 & 2375 & 1965 & 1759 & 1178 & 817 & 589 \\
\hline 5000 & 1500 & 4004 & 3910 & 3823 & 3671 & 3294 & 3031 & 2792 & 2582 & 2065 & 1700 & 1216 & 681 & 520 & 512 \\
\hline 5000 & 2000 & 4069 & 3958 & 3758 & 3483 & 2999 & 2724 & 2511 & 2271 & 1827 & 1457 & 759 & 381 & 371 & 371 \\
\hline 6000 & 100 & 3173 & 3097 & 3006 & 2835 & 2325 & 2012 & 1925 & 1845 & 1691 & 1553 & 1386 & 1045 & 939 & 861 \\
\hline 6000 & 500 & 3694 & 3627 & 3600 & 3569 & 3407 & 3061 & 2853 & 2749 & 2470 & 2173 & 1977 & 1638 & 1353 & 933 \\
\hline 6000 & 1000 & 3706 & 3566 & 3485 & 3425 & 3211 & 3040 & 2768 & 2525 & 2159 & 1948 & 1689 & 1120 & 716 & 458 \\
\hline 6000 & 1500 & 3753 & 3609 & 3503 & 3299 & 2929 & 2681 & 2466 & 2259 & 1886 & 1618 & 1179 & 587 & 447 & 407 \\
\hline 6000 & 2000 & 3874 & 3739 & 3515 & 3153 & 2688 & 2409 & 2209 & 2013 & 1664 & 1358 & 625 & 303 & 295 & 250 \\
\hline 7000 & 100 & 3052 & 2990 & 2910 & 2746 & 2255 & 1939 & 1846 & 1763 & 1607 & 1479 & 1312 & 975 & 864 & 843 \\
\hline 7000 & 500 & 3470 & 3393 & 3386 & 3356 & 3243 & 2926 & 2669 & 2460 & 2223 & 1977 & 1799 & 1480 & 1261 & 905 \\
\hline 7000 & 1000 & 3497 & 3305 & 3194 & 3138 & 3031 & 2890 & 2549 & 2218 & 1908 & 1728 & 1618 & 1011 & 639 & 419 \\
\hline 7000 & 1500 & 3564 & 3355 & 3194 & 2933 & 2664 & 2452 & 2208 & 1987 & 1689 & 1438 & 985 & 459 & 278 & 156 \\
\hline 7000 & 2000 & 3694 & 3501 & 3240 & 2823 & 2437 & 2157 & 1942 & 1780 & 1557 & 1153 & 481 & 246 & 184 & 112 \\
\hline
\end{tabular}

3.2. Analysis. Due to the reliability of the LUT approach, it is widely used to predict $\mathrm{CHF}$ of horizontal flow, $\mathrm{CHF}_{\text {hor }}$, in many industries including nuclear power generation for which accuracy of prediction is crucial. To use the CHF-LUT to predict $\mathrm{CHF}$ occurrence in horizontal tube, the LUT values are adjusted to account for flow stratification. Groeneveld [11] suggested that the CHF for vertical flow, $\mathrm{CHF}_{\text {ver }}$, be multiplied by a stratification factor $K_{\text {strat }}$ such that

$$
\mathrm{CHF}_{\text {hor }}=K_{\text {strat }} \cdot \mathrm{CHF}_{\text {ver }} \text {. }
$$

To determine the stratification factor, the exact flow regime must be known. Figure 5 shows the flow-regime map 


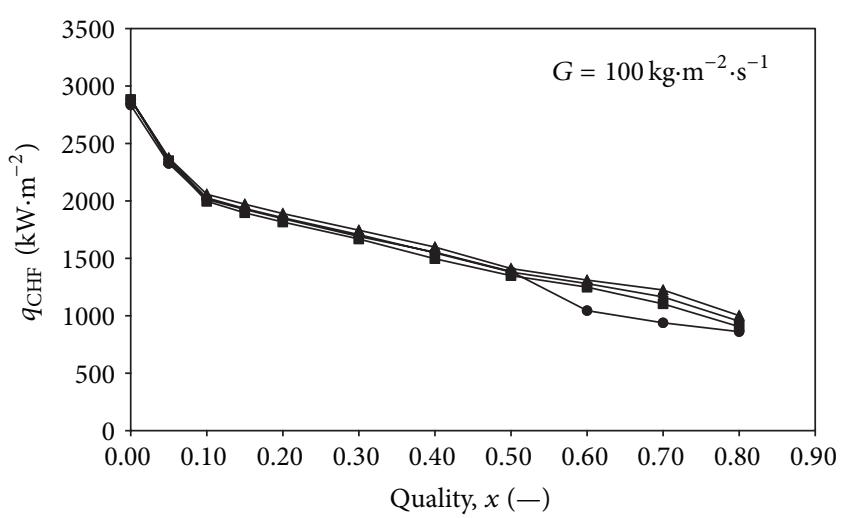

(a)

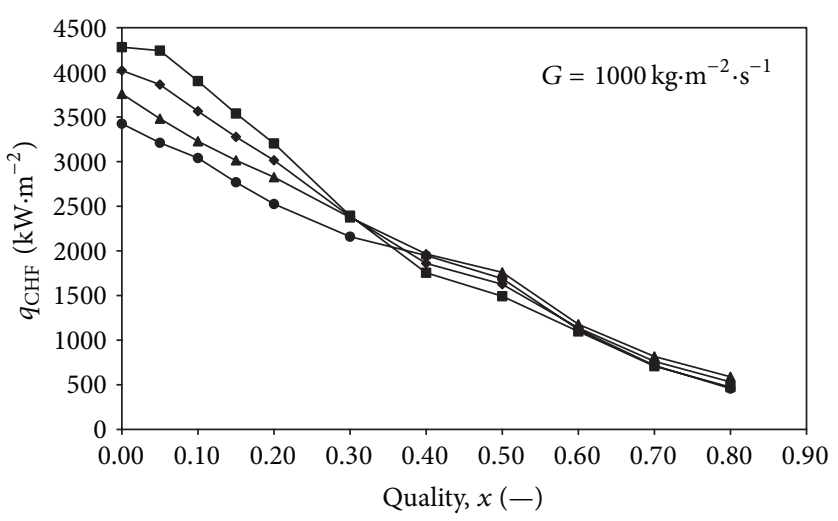

(b)

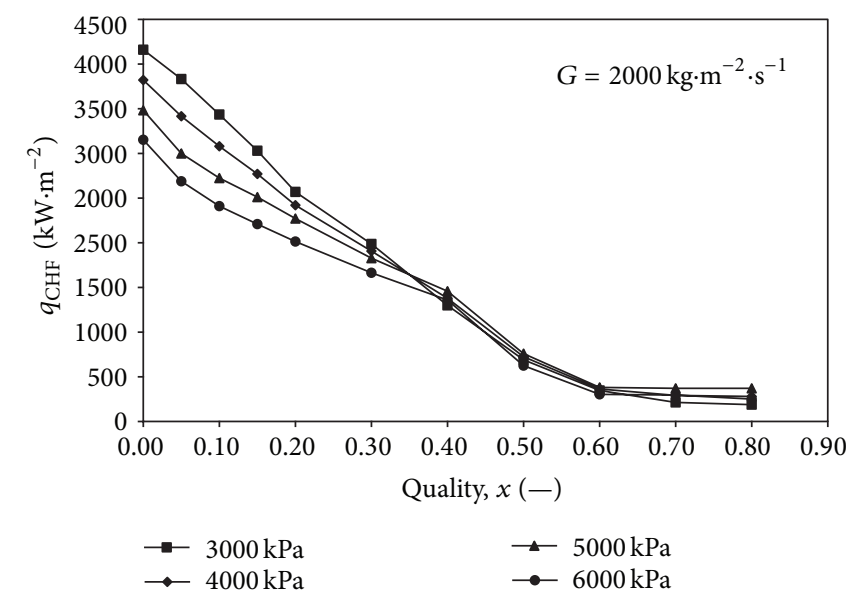

(c)

FIGURE 1: Effect of pressure on CHF for vertical up-flow of water in $67 \mathrm{~mm}$ diameter tube as predicted by CHF-LUT.

TABLE 2: Effect of high heat flux and tube blockage on CHF occurrence for a $67 \mathrm{~mm}$ vertical boiler tube.

\begin{tabular}{lccc}
\hline Parameter & Base case & High heat flux case & 90\% tube blockage \\
\hline Heat flux $\left(\mathrm{KW} \cdot \mathrm{m}^{-2}\right)$ & 100 & 400 & 100 \\
Pressure $(\mathrm{kPa})$ & 6,000 & 6,000 & 6,000 \\
Vertical heated length $(\mathrm{m})$ & 10 & 10 & 10 \\
Inlet quality to vertical tube $(-)$ & 0 & 0 & 0 \\
Mass flux $\left(\mathrm{kg} \cdot \mathrm{m}^{-2} \cdot \mathrm{s}^{-1}\right)$ & 1,000 & 1,000 & 100 \\
Tube exit quality $(-)$ & 0.038 & 0.152 & 0.380 \\
Critical heat flux $\left(\mathrm{kW} \cdot \mathrm{m}^{-2}\right)$ & 3,262 & 2,760 & 1,580 \\
\hline
\end{tabular}

for horizontal flow (modified from Taitel and Dukler [12] by [13]). The modification included the extension of curve D into the annular flow regime (Lockhart-Martinelli's parameter, $X_{\mathrm{LM}}<1.6$ ), resulting in subdivision of the annular regime into homogeneous annular and stratified annular.

For stratified-flow regimes, the liquid waves will not be sufficiently large to cool the upper part of the tube which leads to a CHF value and $K_{\text {strat }}$ of zero. If the flow regime falls in the homogeneous annular region (above the line $\mathrm{DD}^{\prime}$ ), the effect of orientation on the phase distribution is insignificant. The CHF for horizontal flow may be assumed equal to that for vertical flow and $K_{\text {strat }}=1.0$. For flow conditions between curves $\mathrm{A}$ and $\mathrm{D}$, the stratification factor
$K_{\text {strat }}$ varies from zero to unity. As a quick estimate, a linear interpolation was used to evaluate $K_{\text {strat }}$ [14]. However, Wong [13] showed that a large portion of the horizontal $\mathrm{CHF}$ data was underpredicted using direct interpolation. A more accurate prediction method for $K_{\text {strat }}$ was developed by Wong [13]. A dimensionless parameter, $T_{1}$, representing the ratio of turbulence to gravity force was derived as follows:

$$
T_{1}=0.046 \operatorname{Re}_{L}^{-0.2}\left(\frac{1-x}{1-\alpha}\right)^{2} \frac{G^{2}}{g D_{\text {hy }} \rho_{f}\left(\rho_{f}-\rho_{g}\right) \alpha^{0.5}},
$$

where $\operatorname{Re}_{L}$ is liquid Reynolds number, $g$ is gravitational acceleration, $\alpha$ is void fraction, and $\rho$ is density. The subscripts $f$ and $g$ denote saturated liquid and vapor, respectively. 


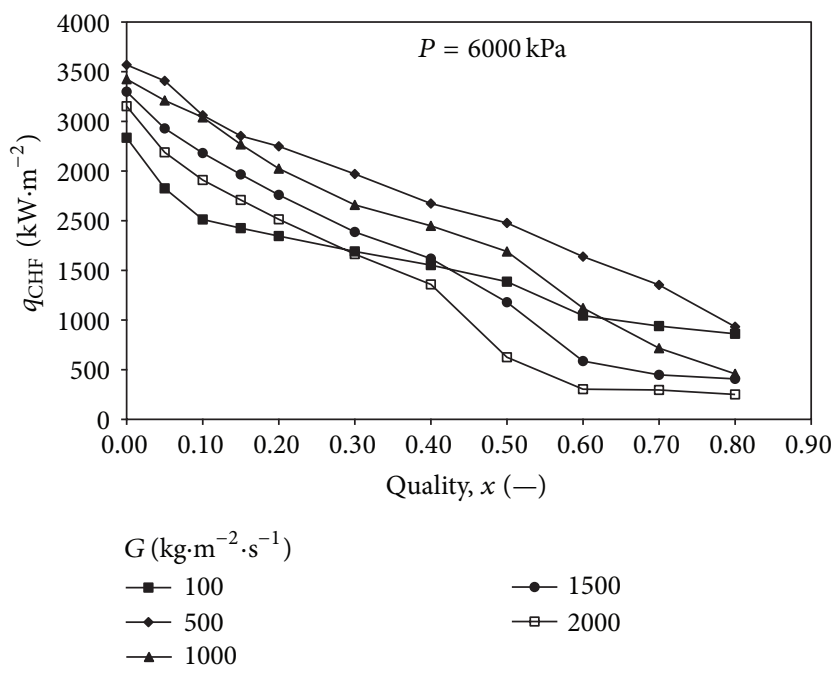

FIGURE 2: Effect of mass flux on CHF for vertical up-flow of water in $67 \mathrm{~mm}$ diameter tube as predicted by CHF-LUT.

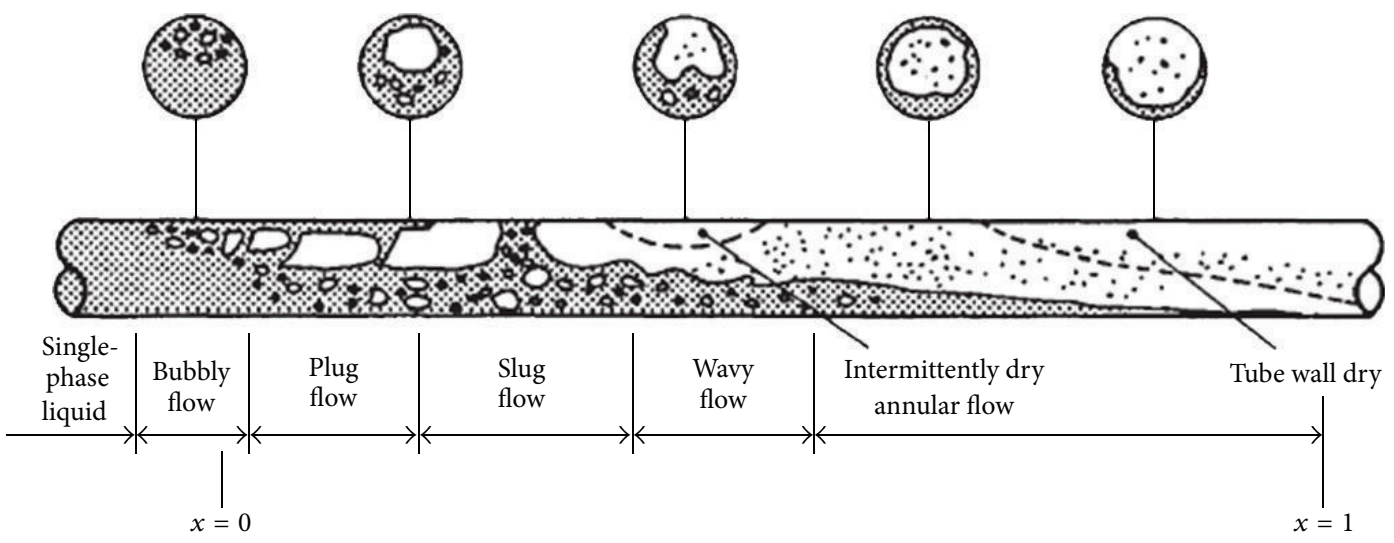

FIGURE 3: Flow patterns during evaporation in horizontal tube with uniform heat flux [10].

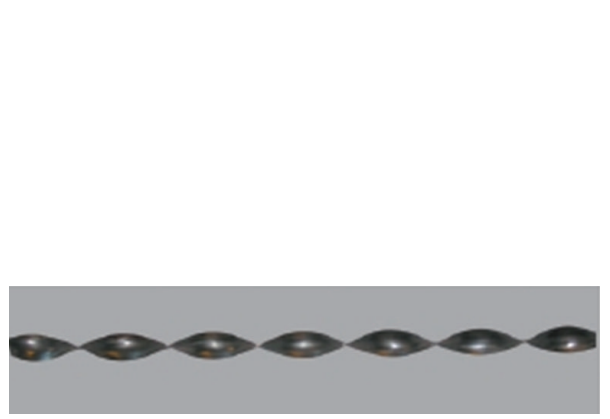

(a)

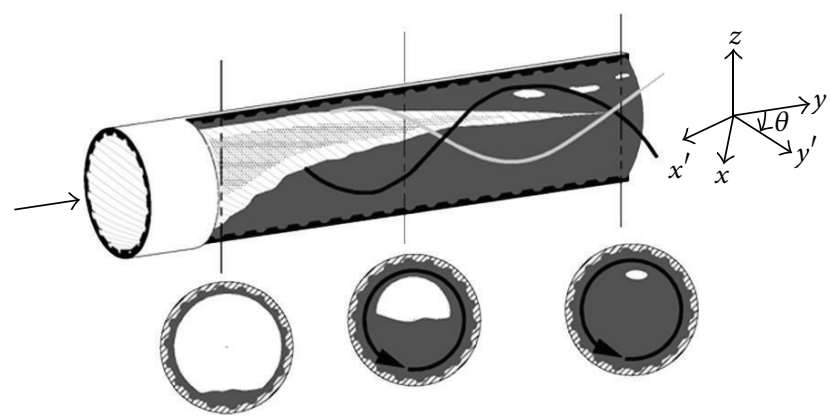

(b)

FIGURE 4: Suggested boiling enhancement geometries: (a) tape tube insert; (b) microfinned tube.

The stratification factor for water was suggested as

$$
K_{\text {strat }}=1-\exp \left[-\left(\frac{T_{1}}{3}\right)^{0.5}\right]
$$

Wong [13] showed that comparing against horizontal $\mathrm{CHF}$ data, prediction using (6) is superior to the method of direct interpolation. $K_{\text {strat }}$ values were found to decrease with increasing tube diameter. The tube diameter correction factor is approximated by [13] as

$$
C_{1}=\left(\frac{0.008}{D_{\text {hy }}}\right)^{0.3} \text {. }
$$




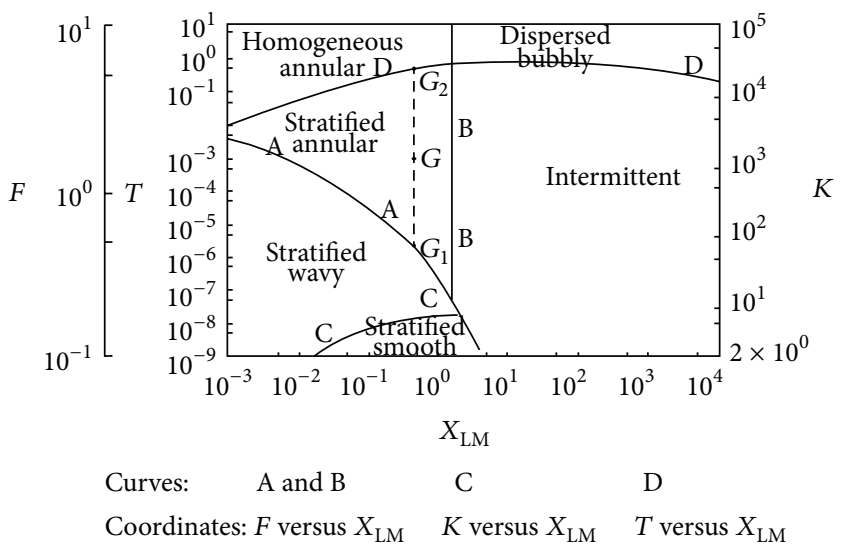

FIgURE 5: Modified, generalized, flow-regime map for horizontal flow [13].

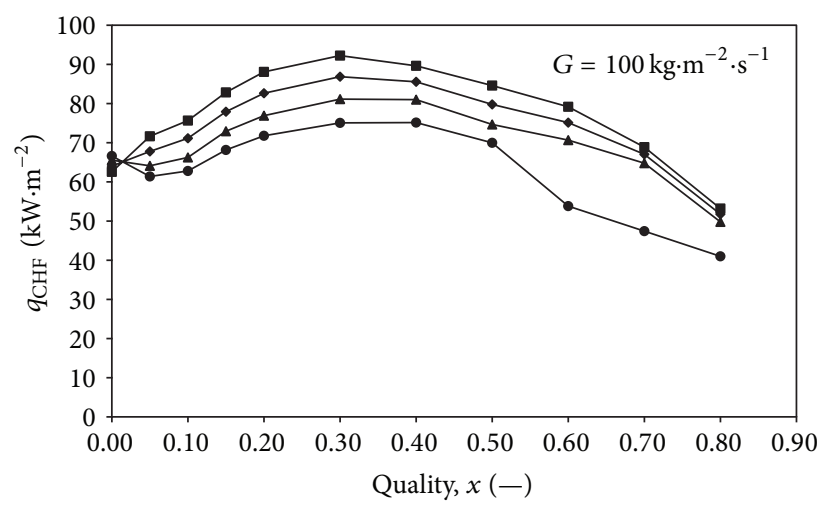

(a)

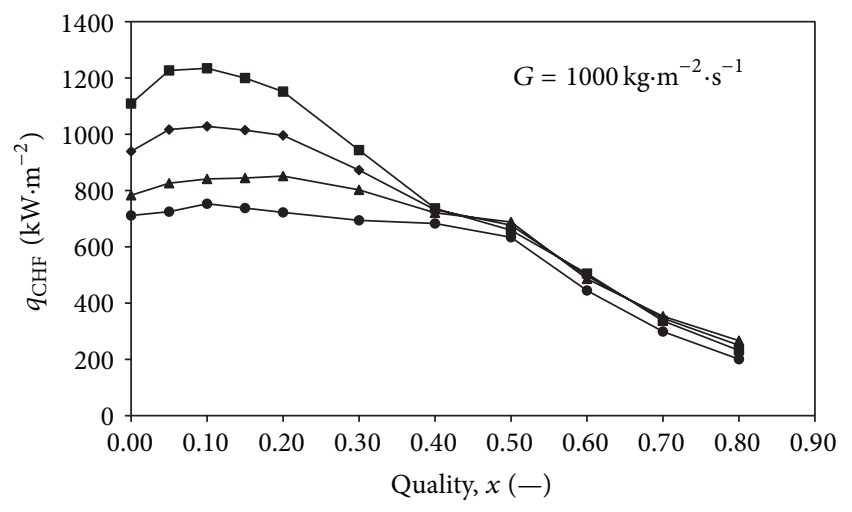

(b)

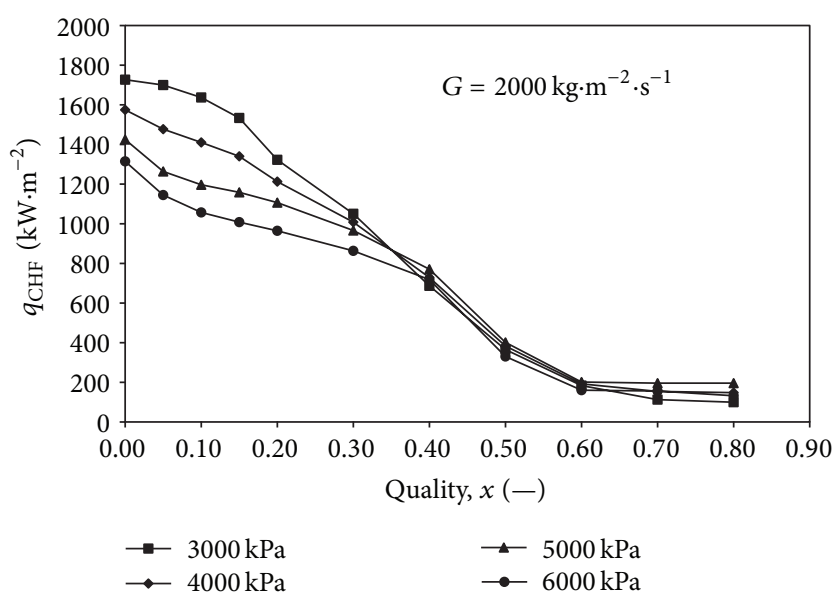

(c)

FIGURE 6: Effect of pressure on CHF for horizontal flow of water in $67 \mathrm{~mm}$ diameter tube as predicted by CHF-LUT.

Therefore, using the table look-up technique, the CHF in a horizontal tube is calculated with

$$
\mathrm{CHF}_{\text {hor }}=\mathrm{C}_{1} K_{\text {strat }} \mathrm{CHF}_{\mathrm{ver}} \text {. }
$$

3.3. Discussion. At the same flow conditions for a horizontal tube and vertical tube, it is more likely for CHF to occur in the horizontal tube first. The main reasons which led to this argument are:

(i) flow stratification may cause partial dryout at low mass fluxes and high qualities;

(ii) the presence of the partial dryout causes a reduction in the CHF value; 


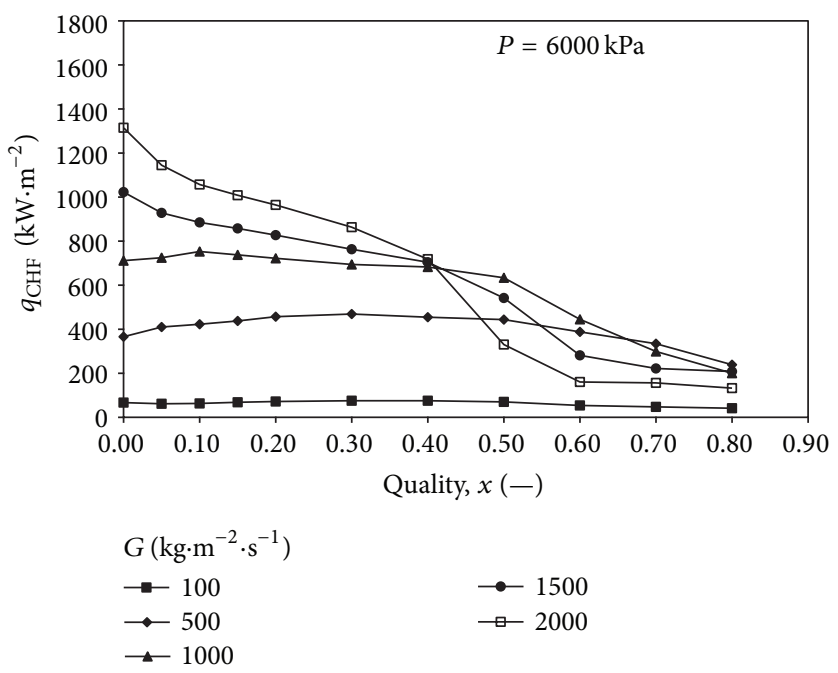

FIGURE 7: Effect of mass flux on CHF for horizontal flow of water in $67 \mathrm{~mm}$ diameter tube as predicted by CHF-LUT.

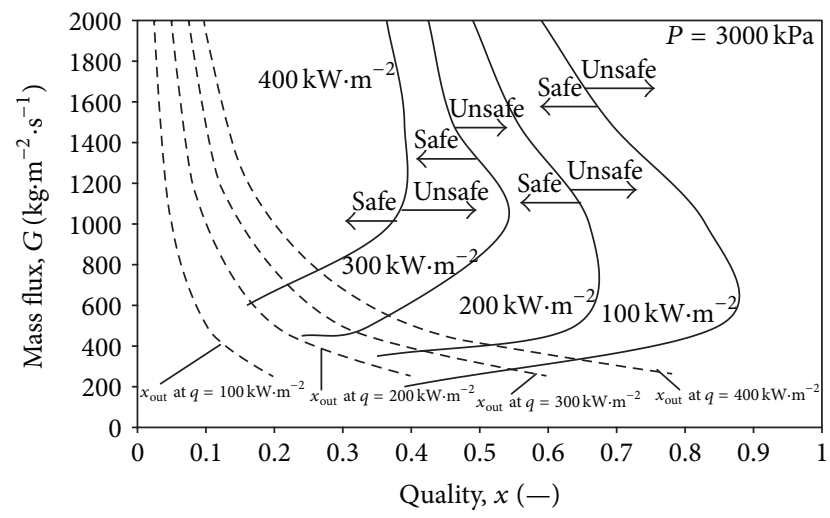

(a)

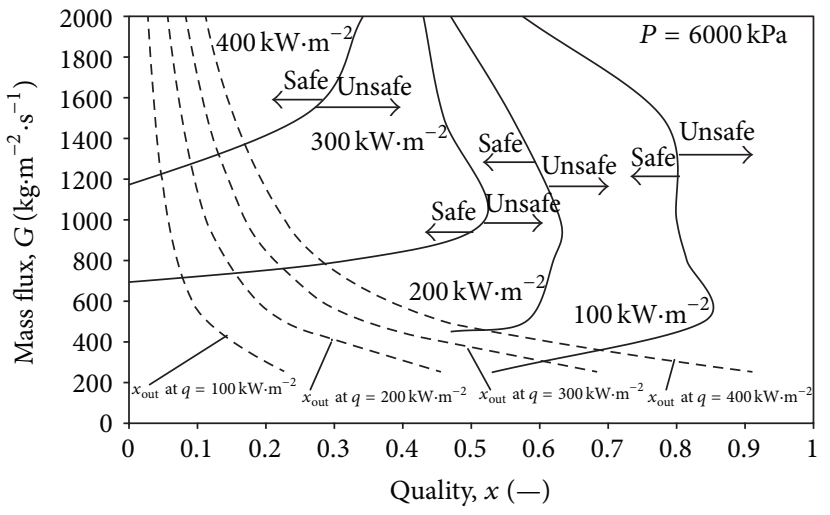

(b)

FIGURE 8: Safety limits of the operation of boiler for $50 \%$ allowable heat flux.

(iii) in addition, corrosion potential is higher due to the change in flow direction and due to partial/complete dryout.

So, more detailed examination is performed on the horizontal flow configuration.

The vertical CHF-LUT was used with (6) and (7) to build a LUT for CHF in horizontal flow. The resulting LUT is shown in Table 3 for the same conditions of the vertical tube table. It is clear in the table that the CHF values are much less for the horizontal flow than those of the vertical flow for the same pressures, mass fluxes, and qualities.

Figure 6 shows the effect of pressure on CHF for different mass fluxes. In all cases, the $\mathrm{CHF}$ value decreases with increasing pressure. In Figure 6(a) one can expect that flow stratification is high which results in low values of $\mathrm{CHF}$ for the whole range of qualities. At higher mass fluxes (Figures 6(b) and 6(c)), the pressure effect is weakened at quality of about 0.4 followed by sudden drop in CHF values. This drop in CHF results from the high quality which leads to stronger effect of flow stratification.
The effect of mass flux on CHF is shown in Figure 7. For qualities less than 0.4 the $\mathrm{CHF}$ value increases with increasing mass flux. At higher qualities, the sudden drop in CHF leads to a reverse effect of mass flux.

Similar to the vertical flow analysis, some cases of boiler operation conditions are investigated and the results are shown in Table 4 . The results show that for the base case (normal operation conditions) the CHF value is seven times higher than the operating heat flux. So for this case, any failure of the boiler tube may result due to other causes than dryout (e.g., corrosion). Although at this CHF value, it is still safe to operate the boiler, the safety margin is much less than that of a vertical flow.

The second case of Table 4 is for high heat flux. In this case, the CHF value is not much higher than the operating heat flux, and CHF could happen for this case. Also for the case of $80 \%$ tube blockage, CHF is very close to the operating heat flux. At $90 \%$ tube blockage the whole flow is affected by flow stratification, and the CHF is lower than the operating heat flux. This is likely to lead to complete dryout of the boiler 
TABLE 3: CHF-LUT for horizontal flow in $67 \mathrm{~mm}$ diameter tube.

\begin{tabular}{|c|c|c|c|c|c|c|c|c|c|c|c|c|c|c|c|}
\hline \multirow{3}{*}{$P(\mathrm{kPa})$} & \multirow{3}{*}{$G\left(\mathrm{~kg} \cdot \mathrm{m}^{-2} \cdot \mathrm{s}^{-1}\right)$} & \multicolumn{14}{|c|}{ Quality, $x(-)$} \\
\hline & & -0.15 & -0.10 & -0.05 & 0.00 & 0.05 & 0.10 & 0.15 & 0.20 & 0.30 & 0.40 & 0.50 & 0.60 & 0.70 & 0.80 \\
\hline & & \multicolumn{14}{|c|}{ Critical heat flux, CHF $\left(\mathrm{kW} \cdot \mathrm{m}^{-2}\right)$} \\
\hline 100 & 100 & 63 & 50 & 35 & 26 & 41 & 52 & 61 & 67 & 76 & 83 & 88 & 87 & 72 & 56 \\
\hline 100 & 500 & 650 & 532 & 465 & 399 & 369 & 405 & 447 & 478 & 478 & 467 & 441 & 358 & 227 & 168 \\
\hline 100 & 1000 & 1347 & 1157 & 1107 & 960 & 729 & 678 & 687 & 666 & 611 & 499 & 491 & 432 & 256 & 129 \\
\hline 100 & 1500 & 1596 & 1426 & 1270 & 1086 & 799 & 731 & 725 & 691 & 628 & 560 & 559 & 481 & 253 & 105 \\
\hline 100 & 2000 & 1637 & 1428 & 1271 & 1090 & 811 & 749 & 737 & 703 & 619 & 578 & 547 & 442 & 203 & 55 \\
\hline 1000 & 100 & 68 & 64 & 58 & 51 & 72 & 78 & 85 & 90 & 92 & 89 & 77 & 61 & 59 & 55 \\
\hline 1000 & 500 & 508 & 497 & 370 & 586 & 748 & 739 & 731 & 727 & 680 & 440 & 341 & 225 & 188 & 183 \\
\hline 1000 & 1000 & 795 & 778 & 1039 & 1272 & 1372 & 1266 & 1197 & 1160 & 871 & 568 & 437 & 281 & 178 & 136 \\
\hline 1000 & 1500 & 1152 & 1128 & 1517 & 1673 & 1687 & 1483 & 1390 & 1279 & 975 & 469 & 280 & 192 & 124 & 111 \\
\hline 1000 & 2000 & 1566 & 1533 & 1625 & 1809 & 1828 & 1566 & 1422 & 1327 & 947 & 414 & 215 & 163 & 103 & 41 \\
\hline 2000 & 100 & 70 & 66 & 62 & 56 & 69 & 73 & 80 & 85 & 89 & 86 & 79 & 68 & 62 & 51 \\
\hline 2000 & 500 & 583 & 576 & 404 & 526 & 654 & 693 & 689 & 675 & 645 & 462 & 432 & 346 & 255 & 209 \\
\hline 2000 & 1000 & 897 & 895 & 957 & 1178 & 1270 & 1230 & 1181 & 1135 & 898 & 650 & 550 & 397 & 260 & 186 \\
\hline 2000 & 1500 & 1217 & 1187 & 1340 & 1522 & 1582 & 1486 & 1401 & 1246 & 982 & 640 & 400 & 259 & 156 & 131 \\
\hline 2000 & 2000 & 1641 & 1611 & 1648 & 1705 & 1700 & 1584 & 1512 & 1342 & 999 & 550 & 290 & 173 & 108 & 70 \\
\hline 3000 & 100 & 71 & 69 & 66 & 63 & 72 & 76 & 83 & 88 & 92 & 90 & 85 & 79 & 69 & 53 \\
\hline 3000 & 500 & 622 & 620 & 426 & 515 & 632 & 697 & 707 & 682 & 660 & 510 & 534 & 465 & 326 & 244 \\
\hline 3000 & 1000 & 908 & 900 & 937 & 1109 & 1227 & 1234 & 1200 & 1151 & 943 & 737 & 659 & 505 & 337 & 232 \\
\hline 3000 & 1500 & 1275 & 1260 & 1341 & 1473 & 1536 & 1504 & 1426 & 1251 & 1010 & 771 & 502 & 318 & 186 & 149 \\
\hline 3000 & 2000 & 1708 & 1689 & 1695 & 1727 & 1700 & 1637 & 1534 & 1323 & 1050 & 687 & 365 & 183 & 112 & 99 \\
\hline 4000 & 100 & 70 & 68 & 65 & 64 & 68 & 71 & 78 & 83 & 87 & 86 & 80 & 75 & 67 & 52 \\
\hline 4000 & 500 & 623 & 619 & 412 & 456 & 538 & 578 & 591 & 596 & 591 & 508 & 504 & 450 & 349 & 261 \\
\hline 4000 & 1000 & 868 & 841 & 845 & 939 & 1016 & 1028 & 1014 & 996 & 872 & 732 & 677 & 496 & 346 & 250 \\
\hline 4000 & 1500 & 1266 & 1246 & 1247 & 1289 & 1272 & 1244 & 1204 & 1114 & 939 & 770 & 541 & 326 & 225 & 207 \\
\hline 4000 & 2000 & 1694 & 1664 & 1613 & 1575 & 1477 & 1410 & 1340 & 1213 & 1008 & 729 & 383 & 192 & 154 & 148 \\
\hline 5000 & 100 & 69 & 67 & 65 & 66 & 64 & 66 & 73 & 77 & 81 & 81 & 75 & 71 & 65 & 50 \\
\hline 5000 & 500 & 622 & 614 & 396 & 400 & 451 & 470 & 485 & 517 & 524 & 499 & 472 & 431 & 364 & 271 \\
\hline 5000 & 1000 & 828 & 784 & 758 & 783 & 826 & 841 & 844 & 851 & 802 & 721 & 688 & 486 & 353 & 266 \\
\hline 5000 & 1500 & 1255 & 1228 & 1156 & 1116 & 1032 & 1009 & 1001 & 985 & 870 & 766 & 575 & 334 & 262 & 265 \\
\hline 5000 & 2000 & 1678 & 1636 & 1530 & 1425 & 1264 & 1196 & 1159 & 1107 & 966 & 770 & 401 & 201 & 196 & 196 \\
\hline 6000 & 100 & 76 & 74 & 72 & 67 & 61 & 63 & 68 & 72 & 75 & 75 & 70 & 54 & 47 & 41 \\
\hline 6000 & 500 & 517 & 503 & 378 & 366 & 410 & 422 & 437 & 457 & 469 & 454 & 444 & 388 & 334 & 239 \\
\hline 6000 & 1000 & 796 & 737 & 705 & 711 & 725 & 753 & 738 & 722 & 694 & 683 & 634 & 445 & 299 & 200 \\
\hline 6000 & 1500 & 1206 & 1166 & 1093 & 1023 & 928 & 885 & 858 & 827 & 763 & 704 & 542 & 281 & 222 & 208 \\
\hline 6000 & 2000 & 1691 & 1587 & 1471 & 1315 & 1145 & 1057 & 1008 & 964 & 863 & 718 & 330 & 160 & 156 & 132 \\
\hline 7000 & 100 & 81 & 79 & 77 & 67 & 58 & 58 & 62 & 65 & 68 & 68 & 63 & 48 & 42 & 38 \\
\hline 7000 & 500 & 422 & 405 & 365 & 339 & 379 & 387 & 389 & 387 & 398 & 391 & 382 & 332 & 295 & 220 \\
\hline 7000 & 1000 & 771 & 701 & 663 & 650 & 649 & 678 & 644 & 600 & 582 & 577 & 581 & 385 & 257 & 177 \\
\hline 7000 & 1500 & 1174 & 1116 & 1026 & 927 & 853 & 802 & 745 & 696 & 656 & 604 & 439 & 215 & 135 & 79 \\
\hline 7000 & 2000 & 1702 & 1525 & 1394 & 1200 & 1049 & 945 & 877 & 837 & 792 & 610 & 254 & 130 & 97 & 59 \\
\hline
\end{tabular}

tubes causing either failure of the tubes or accelerating the corrosion.

To determine the safety limits of the boiler, an allowable heat flux was taken to be $50 \%$ of the corresponding $\mathrm{CHF}$. Figure 8 shows the safety operational limits at different pressure. As the CHF is expected to occur downstream of the flow, corresponding exit qualities are show on the same figure.
The boiler will operate safely as long as the operation conditions are to the left of the heat flux line and the mass flux is above the intersection of the exit quality line and the heat flux line. For example, at a pressure of $6000 \mathrm{kPa}$ and a heat flux of $300 \mathrm{~kW} \cdot \mathrm{m}^{-2}$, the mass flux should not be below $800 \mathrm{~kg} \cdot \mathrm{m}^{-2} \cdot \mathrm{s}^{-1}$ and the quality should be to the left of the $300 \mathrm{~kW} \cdot \mathrm{m}^{-2}$ curve. 
TABLE 4: Effect of high heat flux and tube blockage on CHF occurrence.

\begin{tabular}{lcccc}
\hline Parameter & Base case & High heat flux case & $80 \%$ tube blockage & $90 \%$ tube blockage \\
\hline Heat flux $\left(\mathrm{kW} \cdot \mathrm{m}^{-2}\right)$ & 100 & 400 & 100 & 100 \\
Pressure $(\mathrm{kPa})$ & 6,000 & 6,000 & 6,000 & 15 \\
Heated length $(\mathrm{m})$ & 15 & 15 & 0 & 15 \\
Inlet quality to vertical tube $(-)$ & 0 & 0 & 200 & 0 \\
Mass flux $\left(\mathrm{kg} \cdot \mathrm{m}^{-2} \cdot \mathrm{s}^{-1}\right)$ & 1,000 & 1,000 & 0.285 & 100 \\
Tube exit quality $(-)$ & 0.057 & 0.228 & 173 & 0.570 \\
Critical heat flux $\left(\mathrm{kW} \cdot \mathrm{m}^{-2}\right)$ & 729 & 714 & & 58.8 \\
\hline
\end{tabular}

\section{Procedures of Determining Safety Limits Using the LUT Approach}

The LUT can easily be used to determine the safety limits of boiler operations by applying the following steps.

(1) Determine the operating pressure $(P)$.

(2) Estimate the mass flux $(G)$ in each boiler tube and determine the minimum value. If not possible, determine the average mass flux as

$$
G_{\text {avg }}=\frac{\dot{m}}{A_{c, \text { total }}} .
$$

(3) Calculate the thermodynamic equilibrium quality $(x)$. The CHF occurrence is expected at higher qualities which means downstream of the flow. The quality at any location along the boiling length can be obtained using the heat balance equation such that

$$
x(L)=x_{\text {in }}+\frac{4 q_{\text {operate }}}{D G H_{f g}},
$$

where $x_{\text {in }}$ is the inlet quality, $q$ is the heat flux, and $H_{f g}$ is the latent heat of vaporization.

(4) Use the tube diameter modified CHF-LUT to evaluate $q_{\mathrm{CHF}}=f(P, G, x)$. Interpolation between the values for nongrid points might be necessary.

(5) Compare the operating heat flux to the calculated $\mathrm{CHF}$ value (considering $q_{\mathrm{CHF}}$ uncertainty).

If $q_{\text {operate }}<q_{\mathrm{CHF}}$, then the boiler is operated safely and CHF is unlikely to occur.

If $q_{\text {operate }}>q_{\mathrm{CHF}}$, then the boiler operation exceeds safety limits and accidents may occur.

The CHF-LUT can easily be programmed into a computer code for quick interpolation and other calculations.

\section{Other Considerations}

The CHF-LUTs for this work are developed for steady-state water flow in uniformly heated tubes with inside diameter of $67 \mathrm{~mm}$. During normal operation of reactors, boilers, and steam generators, the heat flux is nonuniform. Also the flow fluctuates in pressure and mass flux. For such cases, the CHFLUTs still can be used with some considerations.

Most CHF measurements have been obtained in uniformly heated tubes because of relative ease in construction of the test section and known location of dryout (downstream end of heated length). Hence, the large majority of $\mathrm{CHF}$ prediction methods were derived based only on the data of uniformly heated channels. A change in axial-flux distribution (AFD) from uniform to nonuniform can have an effect on the location of dryout and magnitude of CHF or dryout power since:

(i) the location of dryout may shift from the downstream end to well upstream from the downstream end (the shift in initial-dryout location depends primarily on the shape of AFD and flow conditions), and

(ii) the location of dryout and magnitude of $\mathrm{CHF}$ is affected by upstream history of the flow (flow memory effect).

Yang et al. [15] performed experimental study on the effect of AFD on CHF. They concluded that the AFD effect on $\mathrm{CHF}$ power is relatively small. The $\mathrm{CHF}$ power increases slightly as a result of AFD change from uniform to nonuniform in addition to the shifting in CHF location at low inlet qualities. This slight increase in CHF, especially at low inlet temperature, makes it more conservative to apply the CHFLUT.

El Nakla [16] showed that the steady-state CHF prediction techniques can be used to predict flow oscillation and flow transients CHF with great accuracy. The method used in such cases is applying the instantaneous local conditions of the flow. For instance, if the flow is oscillating, then it is only needed to determine the flow conditions $(P, G$, and $X)$ at a specific instant, and by using these values along the CHFLUT, the safety limits can be determined as in steady-state cases.

Corrosion of tubes might play a major role in boiler tube failure especially after a sudden turn and in horizontal flow where flow stratification could result in dryout or partial dryout in the tube. Collier and Thome [10] provided that the corrosion in such flow configurations is very quick, and they also summarized some of the previous work on the topic.

\section{Conclusions}

Two look-up tables were developed to predict critical heat flux in vertical and horizontal boilers tubes. The tables are 
applicable for $67 \mathrm{~mm}$ diameter tubes with water as coolant. These tables cover wide range of flow conditions $(P=100-$ $7000 \mathrm{kPa}, G=100-2000 \mathrm{~kg} \cdot \mathrm{m}^{-2} \cdot \mathrm{s}^{-1}$, and $\left.x=-0.15-0.80\right)$ so that they can be used during normal operation as well as during accident scenarios and flow oscillation.

The derived CHF-LUTs show correct asymptotic trends compared to those reported in the literature. The prediction accuracy for the vertical LUT is expected to be better than that of the horizontal one. This is due to the less imposed correction on the vertical flow table and the general practice in applying the table for vertical flow. The results of the analysis showed that the vertical flow will unlikely experience any dryout while the chances are much higher for dryout in the horizontal part.

\section{Conflict of Interests}

The authors declare that there is no conflict of interests regarding the publication of this paper.

\section{Acknowledgments}

The authors would like to acknowledge the support provided by King Abdulaziz City for Science and Technology (KACST) through the Science \& Technology Unit at King Fahd University of Petroleum \& Minerals (KFUPM) and for funding this work through Project no. 10-ENE1371-04 as part of the National Science, Technology and Innovation Plan. The help offered by Saudi Aramco Oil Company is also highly acknowledged.

\section{References}

[1] W. H. McAdams, W. E. Kennel, C. S. Minden, R. Carl, P. M. Picornell, and J. E. Dew, "Heat transfer at high rates to water with surface boiling," Industrial \& Engineering Chemistry, vol. 41, no. 9, pp. 1945-1953, 1949.

[2] D. C. Groeneveld, An Investigation of Heat Transfer in the Liquid Deficient Regime, AECL-3281, Atomic Energy of Canada Ltd., 1969.

[3] D. C. Groeneveld, L. K. H. Leung, P. L. Kirillov et al., "The 1995 look-up table for critical heat flux in tubes," Nuclear Engineering and Design, vol. 163, no. 1-2, pp. 1-23, 1996.

[4] X. C. Huang and S. C. Cheng, "Simple method for smoothing multidimensional experimental data with application to the CHF and postdryout look-up tables," Numerical Heat Transfer $B$, vol. 26, no. 4, pp. 425-438, 1994.

[5] W. P. Baek, H. C. Kim, and S. H. Chang, "An independent assessment of Groeneveld et al's 1995 CHF look-up table," Nuclear Engineering and Design, vol. 178, no. 3, pp. 331-337, 1997.

[6] R. A. Smith, "Boiling inside tubes: critical heat flux for upward flow in uniformly heated tubes," ESDU Data Item 86032, Engineering Science Data Unit International Ltd., London, UK, 1986.

[7] D. Bestion, "The physical closure laws in the CATHARE code," Nuclear Engineering and Design, vol. 124, no. 3, pp. 229-245, 1990.

[8] G. Ulrych, "CHF table applications in KWV PWR design," in Proceedings of the International Workshop on CHF
Fundamentals-CHF Table Improvements, Braunschweig, Germany, March 1993.

[9] W. L. Weaver, R. A. Riemke, R. J. Wagner, and G. W. Johnson, "The RELAP5/MOD3 code for PWR safety analysis," in Proceedings of 4th International Topical Meeting on Nuclear Reactor Thermalhydraulics (NURETH '91), vol. 2, pp. 1221-1226, Karlsruhe, Germany, 1991.

[10] J. G. Collier and J. Thome, Convective Boiling and Condensation, McGraw-Hill, London, UK, 3rd edition, 1994.

[11] D. C. Groeneveld, "A general CHF prediction method for water suitable for reactor accident analysis," C.E.N.G. Report DRE/STT/SETRE/82-2-3/DG, 1982.

[12] Y. Taitel and A. E. Dukler, "A model for predicting flow regime transitions in horizontal and near horizontal gas-liquid flow," ASME 75-WA/HT-29, 1975.

[13] Y. L. Wong, Generalized CHF prediction for horizontal tubes with uniform heat flux [M.S. thesis], University of Ottawa, Ottawa, Canada, 1988.

[14] D. C. Groeneveld, S. C. Cheng, and T. Doan, "1986 AECL-UO critical heat flux lookup table," Heat Transfer Engineering, vol. 7, no. 1-2, pp. 46-62, 1986.

[15] J. Yang, D. C. Groeneveld, L. K. H. Leung, S. C. Cheng, and M. A. E. Nakla, "An experimental and analytical study of the effect of axial power profile on CHF," Nuclear Engineering and Design, vol. 236, no. 13, pp. 1384-1395, 2006.

[16] M. El Nakla, "Establishing an applicable range of conditions of steady-state CHF correlations in transient analyses," COG-082040, S\&L-WP-20934, 2008. 


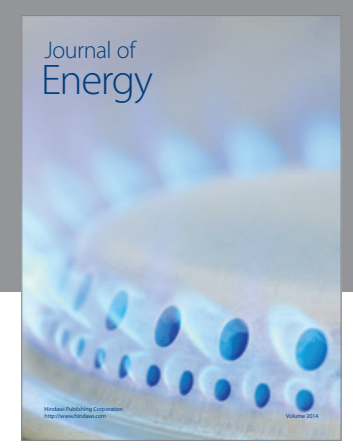

Journal of

Industrial Engineering
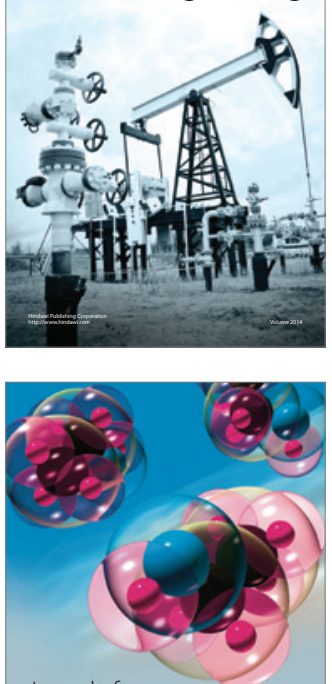

Fuels
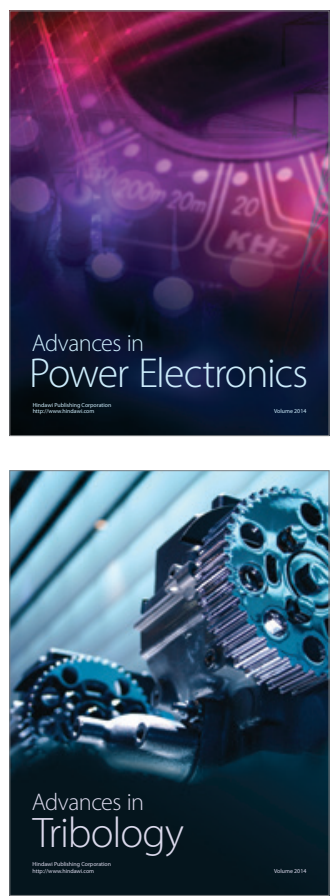

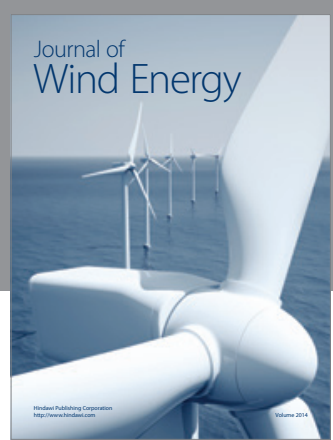

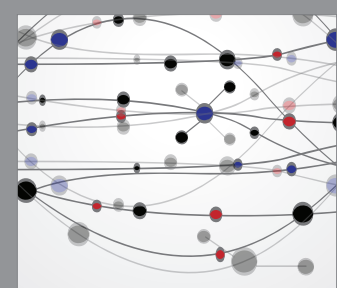

The Scientific World Journal

Submit your manuscripts at http://www.hindawi.com

Journal of

Structures
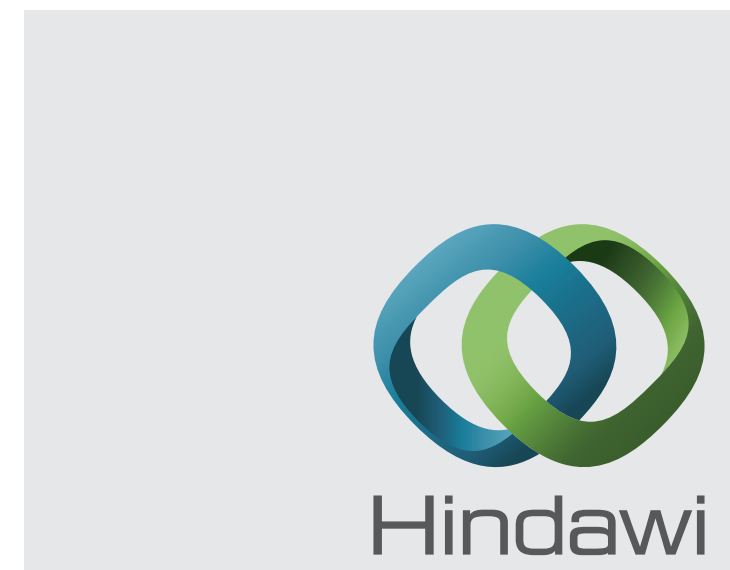

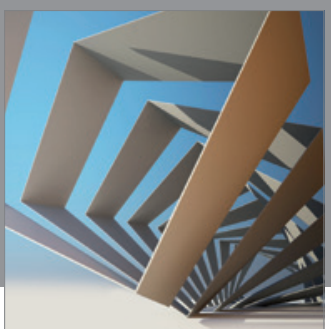

Rotating

Machinery
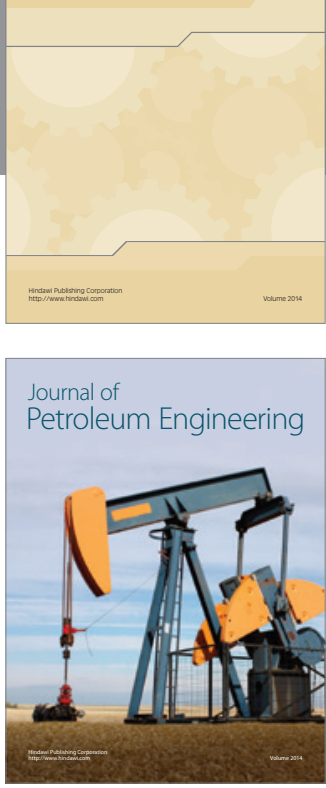

Journal of

Solar Energy
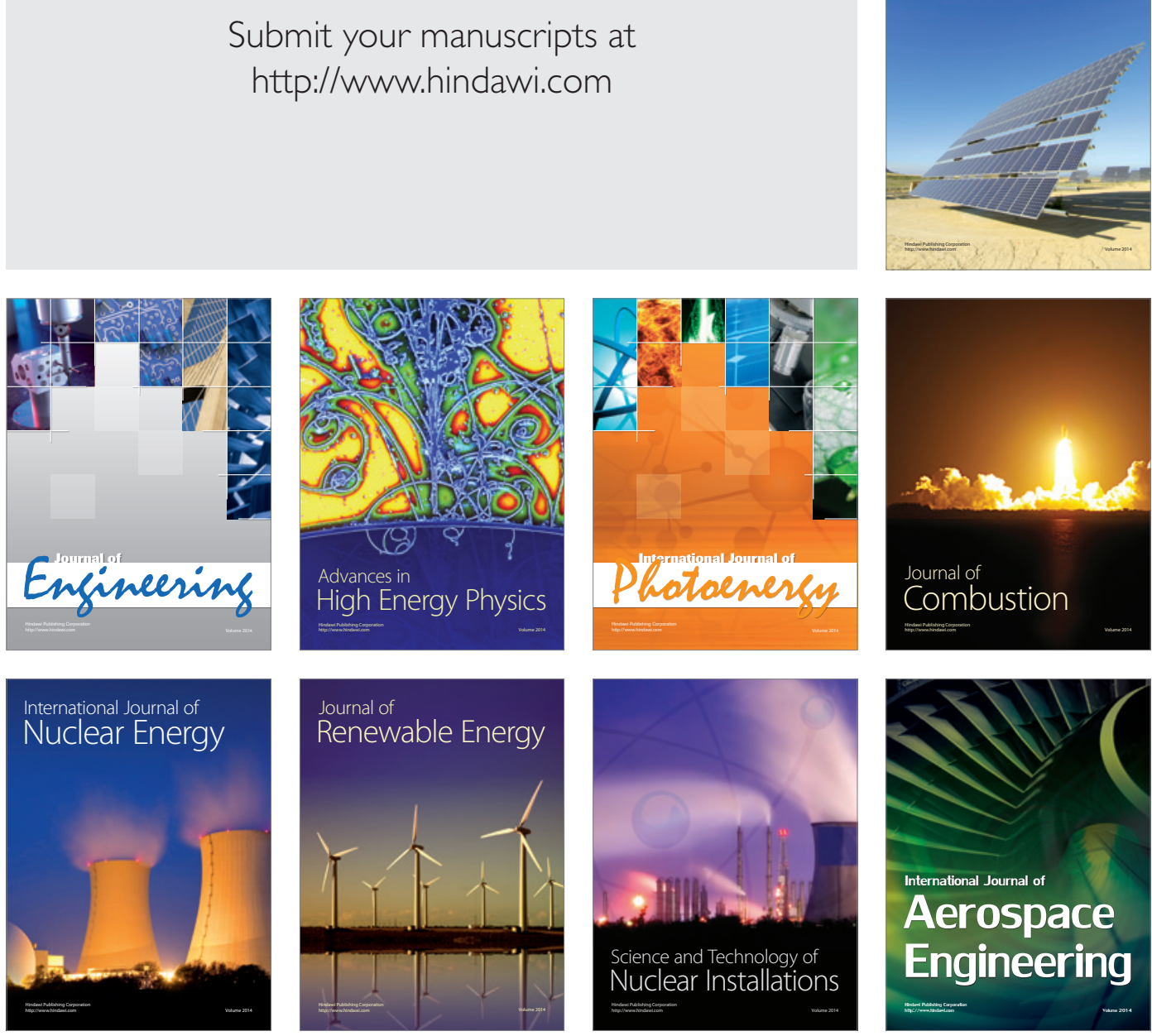